\title{
Safety, feasibility, and effectiveness of virtual pulmonary rehabilitation in the real world
}

This article was published in the following Dove Medical Press journal:

International Journal of COPD

\author{
Liam Knox' \\ Michelle Dunning' \\ Carol-Anne Davies' \\ Rebekah Mills-Bennet ${ }^{\prime}$ \\ Trystan Wyn Sion' \\ Kerrie Phipps' \\ Vicky Stevenson' \\ Claire Hurlin' \\ Keir Lewis ${ }^{1,2}$ \\ 'Hywel Dda University Health Board, \\ UK; ${ }^{2}$ School of Medicine, University of \\ Swansea, Swansea, UK
}

Purpose: To assess the feasibility, safety, and effectiveness of a VIrtual PulmonAry Rehabilitation (VIPAR) program in a real-world setting.

Patients and methods: Twenty-one patients with stable chronic lung disease at a spoke site received (VIPAR) through live video conferencing with a hub where 24 patients were receiving 14 sessions of standard, outpatient, multi-disciplinary pulmonary rehabilitation (PR) in a hospital. We studied three such consecutive PR programs with 6-10 patients at each site. The hub had a senior physiotherapist, occupational therapist, exercise assistant, and guest lecturer, and the spoke usually had only an exercise instructor and nurse present. Uptake, adverse events (AEs), and early clinical changes were compared within and between groups. Travel distances were estimated using zip codes.

Results: Mean attendance was 11.0 sessions in the hub and 10.5 sessions in the spoke $(P=0.65)$. There was a single (mild) AE (hypoglycemia) in all three hub programs and no AEs in the three spoke programs. Mean COPD Assessment Test scores improved from 25.3 to 21.5 in the hub $(P<0.001,95 \%$ CI $2.43-5.17)$ and from 23.4 to $18.8(P<0.001,2.23-7.02)$ in the spoke group, with no difference between the groups $(P=0.51,-3.35-1.70)$. Mean incremental shuttle walk test scores improved from 142 to $208 \mathrm{~m}(P<0.001,75-199)$ in the hub and from 179 to 316 minutes in the spoke $(P<0.001,39.3-92.4)$, with a greater improvement in the spoke $(P=0.025,9.31-133)$. Twenty-one patients saved a total of $8,609.8$ miles over the three programs by having the PR in their local spoke, rather than traveling to the usual nearest (hospital) hub. Conclusion: Video-conferencing, which links a local site to a standard PR program is feasible, safe, and demonstrates at least equivalent short-term clinical gains. Throughput can be increased, with less staffing ratios and significantly less traveling.

Keywords: video-linking, pulmonary rehabilitation, telemedicine, prudent healthcare

\section{Introduction}

Pulmonary rehabilitation (PR) is a multidisciplinary program designed to support people with chronic respiratory impairment. ${ }^{1}$ Although there is heterogeneity between programs, most incorporate exercise, education, and self-management support. ${ }^{1}$ Research consistently demonstrates that PR improves symptoms, quality of life, and exercise capacity. ${ }^{2-5}$ PR has also been shown to reduce admission and readmission rates and length of admission, particularly for patients with COPD. ${ }^{6-8} \mathrm{PR}$ is now recommended as an integral part of care for people with COPD who remain limited by their chest despite optimal pharmacotherapy, ${ }^{9-11}$ and PR is now also advocated for people with bronchiectasis, interstitial lung disease, and pre- and post-thoracic surgery, despite a smaller evidence base. ${ }^{11}$

Despite government recommendations that PR should be available for all those eligible, ${ }^{12}$ only $34.5 \%$ of eligible patients in Wales (UK) were offered PR in $2014 .{ }^{13}$ Our group of hospitals in Hywel Dda University Health Board covers a semi-rural
Correspondence: Liam Knox

Clinical Research Centre, Prince Philip

Hospital, Llanelli SAI 4 8QF, UK

Tel +44 I55 4779307

Fax +44 I55 4779320

Email liam.knox@wales.nhs.uk
International Journal of COPD 2019:14 775-780

(c) (1) (8) ๑ 2019 Knox et al. This work is published and licensed by Dove Medical Press Limited. The full terms of this license are avallable at https://www.dovepress.com/terms.ph

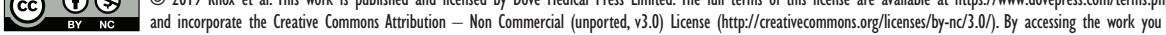
hereby accept the Terms. Non-commercial uses of the work are permitted without any further permission from Dove Medical Press Limited, provided the work is properly attributed. For permision for commercial use of this work, please see paragraphs 4.2 and 5 of our Terms (https://www.doveppess. com/terms.php). 
population of 400,000 people living across a large geographical area (69.2 per square $\mathrm{km}$ population density). Barriers to travel as well as staff recruitment and retention meant only $31 \%$ of our eligible population received $\mathrm{PR}^{13}$ with wide variations in delivery and one county not offering any. National policies recommend more adequate and long-term funding and the strategic use of technology to assist the delivery of PR in rural communities, ${ }^{14}$ particularly as journey time and distance have been shown to independently reduce PR enrollment and completion. ${ }^{15}$ Research investigating the use of technology in healthcare most commonly use telemonitoring as opposed to other mediums. ${ }^{16,17}$ Although such interventions have been linked with positive outcomes, ${ }^{18}$ this has created a gap in the literature investigating asynchronous methods.

To address many of these issues, our PR team implemented a hub and spoke model utilizing video-conferencing (VC) technology to simultaneously connect sites. We wanted to increase the number of people receiving PR but at little extra staff cost; we also wanted to standardize care and deliver it to those in need and closer to home, thus addressing at least three prudent healthcare principles. ${ }^{19}$

\section{Methods}

The aim of the present study was to evaluate the uptake, safety, technical feasibility, and effectiveness of delivering a VIrtual PulmonAry Rehabilitation (VIPAR) program. This is a service evaluation utilizing non-inferiority methodology, comparing people attending a hub site to those attending a spoke site.

\section{Participants}

As this was a service evaluation, the authors did not seek research ethical approval. All participants attending either the hub or spoke site between September 2017 and April 2018 were included. The majority of participants had predominately COPD (GOLD 2019) ${ }^{10}$ with a minority having predominately other chronic lung conditions (Table 1). All participants had moderate to severe COPD, with Medical Research Council (MRC) breathlessness score $\geq 3$, on optimal medications, no exacerbations within 6 weeks, and had varying degrees of airflow obstruction. Individual up-to-date spirometry and comorbidity indexing was not performed at the time of this service evaluation but all participants were screened by appropriate clinicians previously and fulfilled the British Thoracic Society guidelines for suitability and safety to undergo PR. ${ }^{11}$ All were referred by their general practitioner (GP) or respiratory specialist. All participants attended the hub (hospital) for pre-assessment 1-2 weeks before commencing PR; they were offered PR in the closest
Table I Descriptive and inferential statistics for patients at baseline

\begin{tabular}{|c|c|c|c|}
\hline Measures & $\begin{array}{l}\text { Hub } \\
(n=24)\end{array}$ & $\begin{array}{l}\text { Spoke } \\
(n=2 I)\end{array}$ & $P$-value \\
\hline Age (years) & $68.6(12.8)$ & $70.1(10.8)$ & $P=0.67(-8.93-5.79)$ \\
\hline Female & $58.3 \%$ & $33.3 \%$ & $P=0.09(0.25)$ \\
\hline Diagnosis & & & $P=0.45(0.14)$ \\
\hline COPD & $n=19$ & $n=16$ & \\
\hline Bronchiectasis & $n=2$ & $n=1$ & \\
\hline Pulmonary fibrosis & $n=0$ & $n=2$ & \\
\hline Chronic asthma & $n=2$ & $n=1$ & \\
\hline Other & $n=1$ & $n=1$ & \\
\hline CAT & $25.2(6.6)$ & $24.0(6.2)$ & $P=0.52(-2.44-4.77)$ \\
\hline MRC & $3.5(0.9)$ & $3.3(0.8)$ & $P=0.84$ \\
\hline HADS-Depression & $6.5(2.7)$ & $7.05(2.6)$ & $P=0.47(-2.21-1.03)$ \\
\hline HADS-Anxiety & $8.2(3.5)$ & $7.60(4.2)$ & $P=0.60(-1.73-2.95)$ \\
\hline ISWT (meters) & $149(80)$ & $159(133)$ & $P=0.77(-78 . I-58 . I)$ \\
\hline
\end{tabular}

Notes: Data are given as mean and SD (in parenthesis) unless otherwise stated. $P$-values are given with associated confidence intervals. The correlation coefficient is provided for chi-squared tests.

Abbreviations: CAT, COPD Assessment Test; MRC, Medical Research Council breathlessness score; HADS, Hospital Anxiety and Depression Score; ISWT, incremental shuttle walk test.

centre (hub or spoke) and all chose their nearest location. Table 1 describes the groups at baseline.

\section{Hub site}

The program was located in our hospital cardiopulmonary center. It consisted of twice weekly sessions for 7 weeks and incorporated both educational and exercise components according to best practice and current guidelines. ${ }^{6,11} \mathrm{We}$ have reported twice weekly sessions over 7 weeks to have equivalent outcomes as three times weekly over 6 weeks. ${ }^{20}$ Approximately, 7-10 participants attended the hub site for each 7-week program. The course was delivered by an experienced occupational therapist (OT), physiotherapist, and assistant exercise instructor. A supervised, personalized aerobic exercise session of 1-1.5 hours was followed by a 20-40-minute talk delivered by the OT, respiratory nurse, dietician, or respiratory physicians. The OT also offered 1:1 sessions and additional advice on anxiety management, breathlessness control, and breathing exercises for those who wanted.

\section{Spoke site}

The program was conducted in a rural village hall (two cohorts) and community independent living center (one cohort). The hub and spoke sites were linked with the Polycom Real Presence Group 500 Video Conferencing System and Samsung DM65E-BR interactive screens, installed by Comcen. Around 6-8 participants attended the spoke site for the same (simultaneous) 7-week program. A physiotherapy technician (with agreed competencies) helped deliver the 
personalized exercise component, under the direct observation of the staff at the hub site through VC. A respiratory nurse helped monitor participants' safety and prepare gym equipment and VC facilities. The educational components were primarily delivered via VC from the hub in real time. Hub staff were available to travel to the spoke site on their own discretion if they thought more support was needed for a couple of sessions if more complex patients (eg, a lady with resting chronic hypoxia and receiving home ventilation) were attending. This was undertaken by staff on six occasions.

\section{Data collection}

The number of refusers and completers were recorded; any adverse event (AE) was reported by the team and discussed with the clinical lead who categorized it as mild, moderate, or severe, in line with International Conference on Harmonisation Good Clinical Practice guidelines. ${ }^{21}$

Technical issues with the VC (sound, image, connection, etc) were reported and dealt with as they arose.

Participants completed Hospital Anxiety and Depression Score (HADS), MRC dyspnea score, COPD Assessment Test (CAT), and incremental shuttle walk test (ISWT) 1-2 weeks before and on the final session of the PR program.

The amount of travel distance and time saved for the spoke patients attending their local spoke site compared to traveling to the hub site was calculated using zip codes.

\section{Statistical analysis}

We used SPSS version 24. Categorical variables were compared with chi-squared test. Between group changes were compared using independent $t$-tests and Wilcoxon rank-sum tests. Within group changes were measured with repeated mixed ANOVA applying Greenhouse-Geisser correction where the tests for sphericity were violated. Throughout the analysis, alpha error was chosen as 0.05 .

\section{Results}

\section{Safety}

There was one AE of hypoglycemia in a patient with diabetes in the hub. It was treated with a sugary drink and biscuit with complete resolution and classified as mild. There were no reported AEs in the three spoke cohorts. One patient enrolled at the spoke site attended only two sessions and was admitted to the hospital for 6 weeks where she died of a hospital-acquired pneumonia. This was not deemed to be related to the VIPAR project.

\section{Feasibility}

About $61.9 \%$ of patients attended 12 or more sessions in the spoke sites, and $54.6 \%$ attended 12 or more sessions in the hub site. The mean (SD) attendance was 10.5 (4.21) at spoke site and $11.0(2.63)$ at hub site $(P=0.65,95 \% \mathrm{CI}-1.54-2.5)$.

The VC connection was lost in two out of 452 sessions, and sites were reconnected by redialling (the spoke participants continued exercising during these few minutes). Some participants had difficulty hearing a presentation in an early session which was resolved by microphone replacement and the closing of curtains to reduce echo.

\section{Effectiveness}

Figures 1-4 display box and whisker plots showing the change from baseline for both groups for the CAT, ISWT, HADS-Depression (HADS-D), and HADS-Anxiety (HADS-A), respectively. There were significant improvements from baseline in both groups for all four variables $(P<0.003$ throughout $)$.

MRC dyspnoea score also improved for both groups (plot not shown), with a mean change of $-0.48(\mathrm{SD}=0.60)$ for the hub and -0.75 ( $\mathrm{SD}=0.86)$ for the spoke; these changes were both statistically significant $(P<0.002$ and $P<0.003$, respectively). Analysis showed there were no significant differences between groups for MRC dyspnoea score $(P=0.26,95 \% \mathrm{CI}-0.76-0.24)$. Both groups also showed similar improvements in CAT $(P=0.51,95 \%$ CI $-3.35-1.70)$, HADS-D $(P=0.07,95 \%$ $\mathrm{CI}-2.93-0.13)$, and HADS-A $(P=0.18,95 \% \mathrm{CI}-1.29-1.06)$.

The spoke site showed a greater improvement in ISWT (+137 $\mathrm{m})$ compared to the hub site ( $+66 \mathrm{~m} ; P=0.025,95 \%$ CI 9.31-133).

\section{Travel}

The amount of travel distance saved was calculated by determining the difference in miles from the patients' home to the hub site and subtracting the distance from their home to spoke site in those attending the spokes. We multiplied this by the number of sessions that patient attended. The total

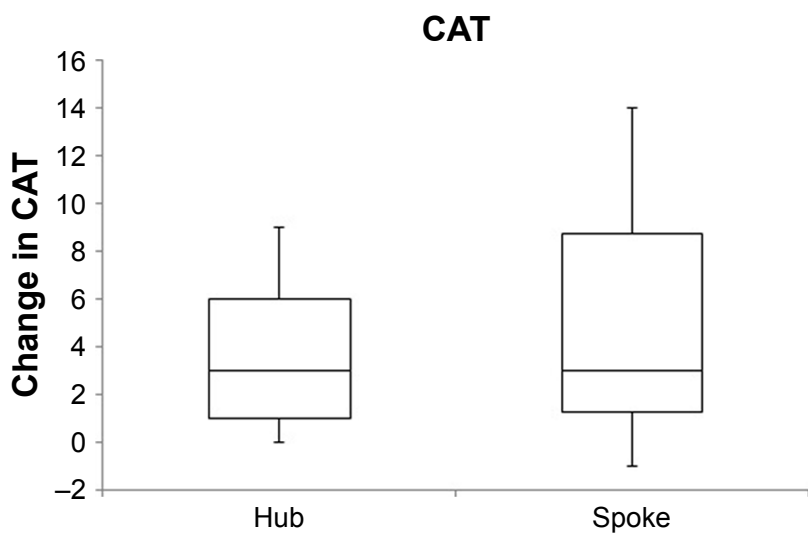

Figure I Box and whisker plot showing change in CAT scores for both groups. Abbreviation: CAT, COPD Assessment Test. 


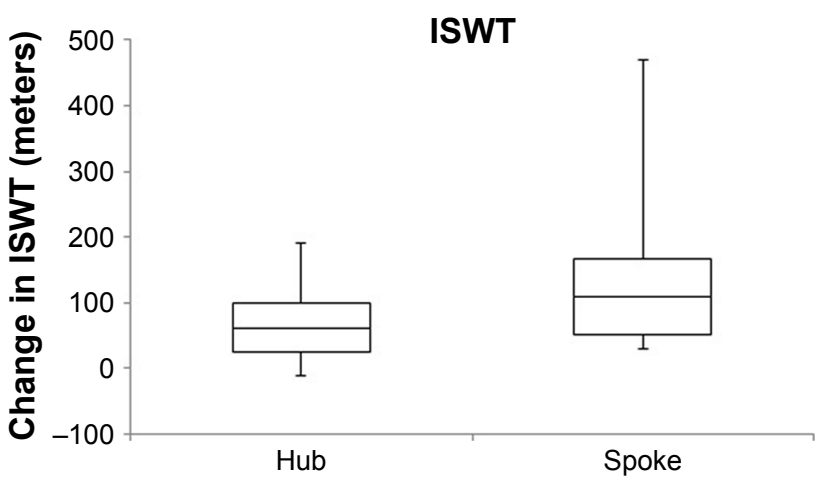

Figure 2 Box and whisker plot showing change in ISWT scores for both groups. Abbreviation: ISWT, incremental shuttle walk test.

travel distance saved over the three cohorts was 8,610 miles at around 410 miles per patient.

Similarly, we compared journey time as estimated by Google Maps. The total travel time saved over the three cohorts was 14,750 minutes averaging 702 minutes or 11.5 hours journey time per spoke patient.

\section{Discussion}

Our VIPAR model is a real-world pragmatic cohort study. Linking a spoke site to a pre-existing program is feasible with good uptake and completion; it appears safe and at least is equally effective in short-term gains in quality of life and walking distance than a standard PR service. Per participant, the staffing ratios and therefore overall costs are less.

Throughout, we developed VIPAR along four prudent healthcare principles. ${ }^{19}$ We developed it using patients' and professionals' opinions through coproduction; we wanted the most effective use of skills and often limited resources (staff and hospital space); we did "what is needed, no more, no less"; we were very keen to reduce inappropriate local variation where large rural areas have no access to PR. ${ }^{14} \mathrm{We}$

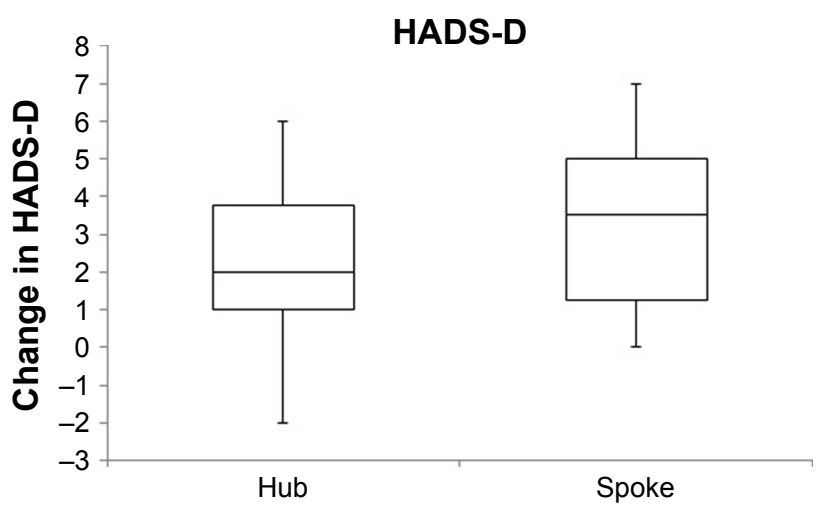

Figure 3 Box and whisker plot showing change in HADS-D scores for both groups. Abbreviation: HADS-D, Hospital Anxiety and Depression Score-Depression.

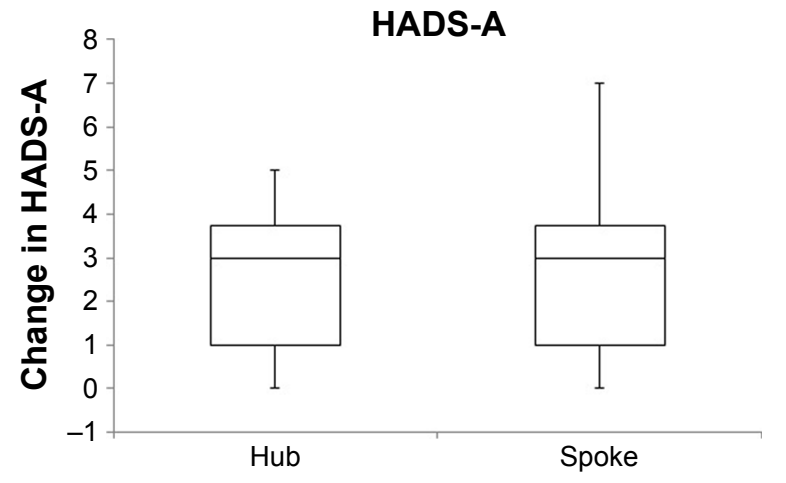

Figure 4 Box and whisker plot showing change in HADS-A scores for both groups. Abbreviation: HADS-A, Hospital Anxiety and Depression Score-Anxiety.

involved staff in the development and implementation of technology alongside technology providers within healthcare, and kept the technology as simple as possible to minimize technical issues. ${ }^{22}$

The uptake of both sites was similar and compare well with the 50\%-90\% uptake values found in the literature; however, a large heterogeneity in uptake rates has been reported. ${ }^{23}$ Interviews with staff and patients and thematic analysis (not reported here) confirms its popularity. The mean attendance rate of $75 \%$ of sessions for the spoke site compares very well to standard PR. ${ }^{24-27}$ This suggests that participants are more willing to attend local groups and neither the spoke nor hub was deterred by VC equipment with no loss of quality of the program on either site through using monitors and remote speakers.

There were no major technical problems embedding and using the VC systems by staff who had minimum training and had never used it to deliver PR. The VC technology also worked in a very rural setting where there is limited Internet service. Our standard clinical (UK-NHS) information technology frameworks allowed National Health Service (NHS) firewalls. Technical issues, such as loss of connectivity, were quickly dealt with and did not require NHS IT Services support. There were no AEs in the spoke site despite lower staffing ratios, and only one minor $\mathrm{AE}$, not related to the $\mathrm{VC}$, was reported during the entire project.

Both groups showed clinically relevant and statistically significant improvements in disease-specific quality of life questionnaires (CAT), ${ }^{27}$ and the spoke group achieved similar results within functional exercise (ISWT). ${ }^{28}$ The hub group, although statistically significant, narrowly missed the minimum clinical difference of improvement in ISWT. ${ }^{28}$ There were similar improvements in generic questionnaires, depression (HADS-D), anxiety (HADS-A), and breathlessness 
scores (MRC) but the clinical importance of a change of 2 (HADS), when the mean baseline scores were in the normal range, remains debatable. Our overall group improvements are similar to traditional models of PR. ${ }^{2-5}$ Although both groups had comparable gains in symptom burden and quality of life, participants in the spoke site showed a significantly bigger increase in ISWT from baseline. The small numbers were influenced by two participants showing exceptional improvements. The hub site did have a lower mean ISWT at baseline which, although not statistically significant, may suggest a more disabled cohort and some selection bias toward fitter people being referred by the GPs to the spoke site. However, as we gain experience, we are rotating more experienced staff to the spoke site if needed, at least for the first two sessions, and so VIPAR is flexible for every cohort.

The VIPAR project saved a total of 8,610 miles of traveling for spoke patients by enabling them to attend a site closer to their homes. This is equivalent to driving to the US and back. Also, 4,750 minutes of traveling was saved, which is equivalent to 10.24 days. This represents a significant ecological impact benefit but is likely to improve outcomes as distance and travel time are independent predictors of poor PR attendance. ${ }^{15}$

The latest Cochrane review of PR concludes:

It is our opinion that additional RCTs comparing pulmonary rehabilitation and conventional care in COPD are not warranted. Future research studies should focus on identifying which components of pulmonary rehabilitation are essential, its ideal length and location, the degree of supervision and intensity of training required and how long treatment effects persist. ${ }^{3}$

Although previous research has shown that PR can be effectively delivered within a home setting, ${ }^{29,30}$ this removes both the supervised exercise and social interaction for patients, where social isolation has been linked to poor health outcomes. ${ }^{31}$ VIPAR fills some of the gaps in the knowledge on community-based PR and offers a degree of supervision, while also suggesting how simple technology can reduce distance and travel time and improve access.

Stickland et al used VC equipment to link a hub and spoke site to deliver PR for people with COPD. ${ }^{32}$ Exercise and educational components were largely similar to those described above; however, their program was held twice weekly for 8 weeks, where 8-12 and 2-6 patients were typically enrolled at the hub and spoke sites, respectively. Their staffing was higher with respiratory therapists and other higher qualified health professionals present at "both" hub and spoke sites, although the exact number was not specified. They found similar gains, where quality of life and functional exercise significantly increased between baseline and follow-up, with no differences between groups. Attendance at both hub (79\%) and spoke (75\%) sites were the same as ours. They did not report any safety or connectivity data and did not include a measure of anxiety or depression nor travel distance and time.

\section{Conclusion}

Future work would be to add a second spoke site to the hub and measure feasibility, safety, and throughput. We are also measuring health contacts and admissions in the year following VIPAR. It can also be used to "top-up" PR or test stroke, cardiac, and cancer rehabilitation models, especially where a shortage of staff and rurality preclude local delivery. Any model should use mobile VC and rotate hub and spoke sites to address local needs and greatest needs first (eg, longest waiting lists).

\section{Acknowledgment}

We thank Comcen, Polycom, Bevan Commission, and the Respiratory Health Implementation Group.

\section{Disclosure}

The authors report no conflicts of interest in this work.

\section{References}

1. National Institute for Health and Care Excellence. Chronic obstructive pulmonary disease in over 16s: diagnosis and management. NICE Guideline. 2011;1-60.

2. Corhay JL, Dang DN, Cauwenberge HV, Louis R. Pulmonary rehabilitation and COPD: providing patients a good environment for optimizing therapy. Int J Chron Obstruct Pulmon Dis. 2014;9:27-39. doi:10.2147/ COPD.S52012

3. McCarthy B, Casey D, Devane D, Murphy K, Murphy E, Lacasse M. Pulmonary rehabilitation for chronic obstructive pulmonary disease. Cochrane Database Syst Rev. 2015;(2). Art. No.: CD003793. doi:10.1002/14651858/CD003793.pub3.

4. Puhan MA, Spaar A, Frey M, et al. Early versus late pulmonary rehabilitation in chronic obstructive pulmonary disease patients with acute exacerbations: a randomized trial. Respiration. 2012;83:499-506. doi:10.1159/000329884

5. Ries AL, Bauldoff GS, Carlin BW, et al. Pulmonary rehabilitation: joint ACCP/AACVPR evidence-based clinical practice guidelines. Chest. 2007;131(5 Suppl 1):S4-S42. doi:10.1378/chest.06-2418

6. Griffiths TL, Burr ML, Campbell IA, et al. Results at 1 year of outpatient multidisciplinary pulmonary rehabilitation: a randomised controlled trial. Lancet. 2000;355(9201):362-368. doi:10.1016/S01406736(99)07042-7

7. Griffiths TL, Phillips CJ, Davies S, Burr ML, Campbell IA. Cost effectiveness of an outpatient multidisciplinary pulmonary rehabilitation programme. Thorax. 2001;56(10):779-784.

8. Seymour JM, Moore L, Jolley CJ, et al. Outpatient pulmonary rehabilitation following acute exacerbations of COPD. Thorax. 2010;65(5): 423-428. doi:10.1136/thx.2009.124164 
9. Vogiatzis I, Rochester CL, Spruit MA, Troosters T, Clini EM. Increasing implementation and delivery of pulmonary rehabilitation: key messages from the new ATS/ERS policy statement. Euro Resp J. 2016;47: 1336-1341. doi:10.1183/13993003.02151-2015

10. Goldcopd.org [homepage on the Internet]. Global strategy for the diagnosis, management, and prevention of COPD - 2019. Available from: https://goldcopd.org/. Accessed January 9, 2019.

11. Bolton CE, Bevan-Smith EF, Blakey JD, et al; British Thoracic Society Pulmonary Rehabilitation Guideline Group. BTS guidelines on pulmonary rehabilitation in adults. Thorax. 2013;68(Supp12):ii1-ii30. doi:10.1136/thoraxjnl-2013-203808

12. Cymru.gov.uk [homepage on Internet]. Together for health - a respiratory health delivery plan [published 2014]. Available from: https:// www1.bps.org.uk/system/files/consultationpapers/131021deliveryplanen.pdf. Accessed September 24, 2018.

13. Baxter N, Holzhauer-Barrie J, McMillan V, Saleem KM, Skipper E, Roberts CM. Time to Take a Breath: National Chornic Obstructive Pulmonary Disease (COPD) Audit Programme: National COPD Primary Care Audit (Wales) 2014-15. London: RCP; 2016.

14. Cymru.gov.uk [homepage on Internet]. Respiratory health delivery plan 2018-2020 [published 2018]. Available from: https:/gov.wales/ docs/dhss/publications/180119respiratory-planen.pdf. Accessed September 24, 2018.

15. Sabit R, Griffiths TL, Watkins AJ, et al. Predictors of poor attendance at an outpatient pulmonary rehabilitation programme. Resp Med. 2008; 102(6):819-824. doi:10.1016/j.rmed.2008.01.019

16. Kotb A, Cameron C, Hsieh S, et al. Comparative effectiveness of different forms of telemedicine for individuals with heart failure (HF): a systematic review and network meta-analysis. PLoS One. 2015; 10(2):e0118681. doi:10.1371/journal.pone.0118681

17. Knox L, Rahman RJ, Beedie C. Quality of life in patients receiving telemedicine enhanced chronic heart failure disease management: a meta-analysis. J Telemed Telecare. 2017;23(7):639-649. doi:10.1177/ $1357633 X 16660418$

18. Bourne S, DeVos R, North M, et al. Online versus face-to-face pulmonary rehabilitation for patients with chronic obstructive pulmonary disease: randomised controlled trial. BMJ Open. 2017;7(7):e014580. doi:10.1136/bmjopen-2016-014580

19. Drakeford M. Making prudent healthcare happen. Address given at: Prudent Healthcare Conference; July 9, 2015; Cardiff, Wales.

20. Lewis KE, Thatcher L, Davies CA, Hodgson P, Jones CL, Hutchings HA. Twice versus three-times weekly pulmonary rehabilitation in a real-life clinical setting. F1000Res. 2014;3:89. doi:10.12688/ f1000research.4047
21. International Conference on Harmonisation Steering Committee. Clinical Safety Data Management: Definitions and Standards for Expedited Reporting. ICH Harmonised Tripartite Guideline. In: International Conference on Harmonisation of Technical Requirments for Registration of Pharmacuticals for Human Use; November 27-30, 1995; Yokohama, Japan.

22. Damhus CS, Emme C, Hansen H. Barriers and enablers of COPD telerehabilitation - a frontline staff perspective. Int J Chron Obstruct Pulmon Dis. 2018;13:2473-2482. doi:10.2147/COPD.S167501

23. Fischer MJ, Scharloo M, Abbink JJ, et al. Drop-out and attendance in pulmonary rehabilitation: the role of clinical and psychosocial variables. Resp Med. 2009;103(10):1564-1571. doi:10.1016/j.rmed.2008.11.020

24. Cockram J, Cecins N, Jenkins S. Maintaining exercise capacity and quality of life following pulmonary rehabilitation. Respirology. 2006; 11(1):98-104. doi:10.1111/j.1440-1843.2006.00791.x

25. Cote CG, Celli BR. Pulmonary rehabilitation and the BODE index in COPD. Eur Respir J. 2005;26(4):630-636. doi:10.1183/09031936.05. 00045505

26. Garrod R, Marshall J, Barley E, Jones PW. Predictors of success and failure in pulmonary rehabilitation. Euro Resp J. 2006;27(4):788-794. doi:10.1183/09031936.06.00130605

27. Kon SS, Canavan JL, Jones SE, et al. Minimum clinically important difference for the COPD Assessment Test: a prospective analysis. Lancet Resp Med. 2014;2(3):195-203. doi:10.1016/S2213-2600(14)70001-3

28. Singh SJ, Jones P, Evans R, Morgan M. The minimum clinically important improvement for the incremental shuttle walking test. Thorax. 2008;63(9):775-777. doi:10.1136/thx.2007.081208

29. Holland AE, Mahal A, Hill CJ, et al. Home-based rehabilitation for COPD using minimal resources: a randomised, controlled equivalence trial. Thorax. 2017;72(1):57-65. doi:10.1136/thoraxjnl-2016-208514

30. Maltais F, Bourbeau J, Shapiro S, et al. Effects of home-based pulmonary rehabilitation in patients with chronic obstructive pulmonary disease: a randomized trial. Ann Intern Med. 2008;149(12):869-878.

31. Holt-Lunstad J, Smith TB, Baker M, Harris T, Stephenson D. Loneliness and social isolation as risk factors for mortality: a meta-analytic review. Perspect Psychol Sci. 2015;10(2):227-237. doi:10.1177/1745691 614568352

32. Stickland MK, Jourdain T, Wong EY, Rodgers WM, Jendzjowsky NG, MacDonald GF. Using Telehealth technology to deliver pulmonary rehabilitation to patients with chronic obstructive pulmonary disease. Can Resp J. 2011;18(4):216-220.
International Journal of COPD

\section{Publish your work in this journal}

The International Journal of COPD is an international, peer-reviewed journal of therapeutics and pharmacology focusing on concise rapid reporting of clinical studies and reviews in COPD. Special focus is given to the pathophysiological processes underlying the disease, intervention programs, patient focused education, and self management protocols.

\section{Dovepress}

This journal is indexed on PubMed Central, MedLine and CAS. The manuscript management system is completely online and includes a very quick and fair peer-review system, which is all easy to use. Visit http://www.dovepress.com/testimonials.php to read real quotes from published authors. 